\title{
Effect of the Greek Solutions for Wellness weight management program on quality of life and associated factors in patients with a psychiatric disorder receiving psychotropic medication
}

\author{
Vassiliki Psarra ${ }^{1,2^{*}}$, Vangelis Drossinos ${ }^{1}$, Maria-Vassiliki Mantellou ${ }^{1}$, Kostas Ntzamaras ${ }^{1}$, Catherine Beal ${ }^{1}$ \\ From $1^{\text {st }}$ International Congress on Neurobiology and Clinical Psychopharmacology and European \\ Psychiatric Association Conference on Treatment Guidance \\ Thessaloniki, Greece. 19-22 November 2009
}

\section{Background}

Weight gain is a major side effect of treatment with psychotropic agents [1]. Besides its adverse metabolic effects, weight gain may also impair physical functioning and quality of life (QoL) [2]. Clinical weight management programs are reported to improve quality of life in obese individuals not receiving psychotropic therapy [3], but this has not been sufficiently investigated in patients with psychiatric disorders.

The primary objective of this study is to assess the impact of the Greek Solutions for Wellness (SfW) 3-month program, which focuses on nutrition and physical exercise, on QoL in patients with a psychiatric disorder who are taking psychotropic medication and have a weight problem. Secondarily it aims to investigate the impact of baseline patient variables (e.g. age, sex, diagnosis) on QoL at month 3.

\section{Materials and methods}

This 26-week prospective observational study enrolled 359 patients from outpatient settings routinely carrying out the Greek SfW, from 23/JAN/2007 to 27/FEB/ 2008. 297 of them entered the program while 62 others who declined, were used as a control group. The QoL instrument Subjective Well-Being under Neuroleptics (SWN), the Clinical Global Impression (CGI) scale, weight (kg), body mass index (BMI, kg/m2) and waist circumference $(\mathrm{WC})(\mathrm{cm})$ were collected at baseline, months 3 (program completion) and 6 (follow

${ }^{1}$ Medical Department of Clinical Research, Pharmaserve-Lilly, 15th KLM National Road Athens-Lamia, 14564 Kifissia, Greece up visit). In addition, diagnosis, disorder duration, treatment regimen and demographic characteristics (age, sex) were recorded. The proportion of patients with a QoL improvement (any SWN increase) was estimated together with their $95 \% \mathrm{CI}$ in both groups at month 3 . Further, stepwise logistic regression models were fitted to adjust the SfW effect on QoL at month 3, controlling for baseline potential confounders and first-degree interactions. A sensitivity analysis was conducted after implausible WC values were found in the database.

\section{Results}

Patient characteristics were similar across both groups: Out of 359 patients, a total of 198 (55.2\%) were female, the mean age (SD) was 40.6 years (10.9), mean weight (SD) $92.9 \mathrm{~kg}$ (17.9), mean BMI (SD) $32.2 \mathrm{~kg} / \mathrm{m} 2$ (5.6). $52.4 \%$ of the patients presented with schizophrenia, $30.9 \%$ with bipolar disorder and $16.7 \%$ other. The mean illness duration was 10.6 years $(\mathrm{SD}=8.7)$. Out of 353 patients still in the study at month 3, 352 were assessable in terms of SWN increase: 206 patients out of 295 in the SfW group $(69.8 \%)(95 \% \mathrm{CI}=[64.2,75.0])$ showed QoL improvement and 33 out of $57(57.9 \%)(95 \% \mathrm{CI}=$ [44.1, 70.9]) in the control group. After controlling for baseline potential confounders the difference between the two groups was ORinitial $=1.43[0.76 ; 2.67]$; ORsensitivity $=1.44[0.77 ; 2.71]$. Covariates significantly associated with an improved QoL at month 3 included a low SWN score (ORinitial $=$ ORsensitivity $=0.94[0.92$; 0.96 ) and a low CGI-S level (ORinitial $=$ ORsensitivity $=$ $0.62[0.49 ; 0.79])$. 


\section{Conclusions}

QoL improvement at 3 months in patients with mental illness as well as weight problems and on psychotropics was associated with low baseline SWN and CGI-S scores, while the big majority of the patients following the Greek SfW program reported an improved QoL.

\section{Acknowledgements}

The Hellenic EY-ZHN Study Team

\section{Author details}

'Medical Department of Clinical Research, Pharmaserve-Lilly, 15th KLM National Road Athens-Lamia, 14564 Kifissia, Greece. ${ }^{2}$ Lilly UK, Erl Wood Manor, Windlesham, Surrey, GU20 6PH, UK.

Published: 22 April 2010

\section{References}

1. Casey DE: Metabolic issues and cardiovascular disease in patients with psychiatric disorders. Am J Med 2005, 118(Suppl 2):15S-22S.

2. Kawachi I: Physical and psychological consequences of weight gain. J Clin Psychiatry 1999, 60(Suppl 21):5-9.

3. Blissmer B, Riebe D, Dye G, Ruggiero L, Greene G, Caldwell M: Health -related quality of life following a clinical weight loss intervention among overweight and obese adults: intervention and 24 month followup effects. Health and Quality of Life Outcomes 2006, 4:43.

doi:10.1186/1744-859X-9-S1-S179

Cite this article as: Psarra et al:: Effect of the Greek Solutions for Wellness weight management program on quality of life and associated factors in patients with a psychiatric disorder receiving psychotropic medication. Annals of General Psychiatry 2010 9(Suppl 1): S179.

\section{Submit your next manuscript to BioMed Central} and take full advantage of:

- Convenient online submission

- Thorough peer review

- No space constraints or color figure charges

- Immediate publication on acceptance

- Inclusion in PubMed, CAS, Scopus and Google Scholar

- Research which is freely available for redistribution

Submit your manuscript at www.biomedcentral.com/submit 